\section{Honours shouldn't be handed out until after the public covid-19 inquiry}

\section{As the UK surpasses 175000 covid related deaths, Phil Hammond argues that we should wait for the findings of a public inquiry before honouring those involved in our pandemic response}

\section{Phil Hammond retired NHS doctor}

We should wait until after the UK government's covid-19 inquiry has reached its conclusions before deciding who deserves to be honoured for the UK's pandemic performance. The government's scientific advisers have undoubtedly worked very hard during the pandemic, monitoring and analysing data to come up with advice that often hasn't been followed. They have also faced widespread abuse and vilification, which alone might qualify them for recognition in the New Year's honours. And it's hard to argue with Patrick Vallance, the UK's chief scientific adviser, when he tweeted, on 1 January 2022; "I am really pleased to see so many outstanding scientists and engineers recognised in this year's honours, including those that have been working tirelessly as part of the response to the covid-19 pandemic."

However, if we are going to commit a vast sum of public money to a lengthy public inquiry, it must get as close to the truth as possible, and be frank and fearless in its findings. It should focus on learning and understanding rather than blame, praising contributions where appropriate, but also holding advisers and decision makers to account. Even before omicron, we have spent close to $£ 400$ billion "managing" the pandemic, and yet have some of the highest rates of covid deaths, long covid, and excess deaths from all causes (and at younger ages) in the world. We have inflicted widespread educational, emotional, and economic harm on ourselves. We too often put children-our future-last.

Too many of our health and care workers have died, and far more are suffering from long covid or the lasting, moral harm of working incredibly hard in unsafe situations, yet being unable to offer a decent and timely standard of care to all those who need it. For much of this pandemic, we gave a very good impression of simply not being up to the task. Boris Johnson's leadership as prime minister has had all the hallmarks of a Greek tragedy. How could any advisor persuade a government to follow the science when so many of its staff flouted their own lockdown rules? This persistent misconduct in public office combined with the acrimonious "divorce" between Johnson and his former adviser Dominic Cummings threatens to dominate any inquiry. And yet as one of the wealthiest countries in the world, with some of the best bench scientists and public health experts, we clearly could and should have done much better. We need to understand what went wrong before handing out the gongs.

The danger of honouring people who will undoubtedly be called to give evidence at the inquiry is that it pre-judges their contribution and perhaps makes it harder for the inquiry to criticise them.
Advisers in turn may be more reluctant to criticise the government if they have received an honour. Our chances of getting to the truth may be lessened. At the very least, it adds fuel to the fire of those who view public inquiries as an establishment stitch up.

The pandemic public inquiry is to be chaired by Baroness Heather Hallett. The remit has yet to be agreed, but no country has emerged unscathed from covid-19, and the UK's performance will in part be benchmarked against other countries. We already have the excellent People's Covid Inquiry Report and a joint Parliamentary Inquiry into lessons learnt, both of which found we were slow to react to the threat of exponential viral growth. ${ }^{12}$ The latter concluded our pre-vaccination pandemic management was derailed by groupthink and was "one of the most important public health failures the United Kingdom has ever experienced.” The wide-ranging Independent Panel Report convened by the World Health Organisation also highlighted the large number of wealthy countries who mistakenly opted for a "wait and see" approach, and concluded that future pandemics could be prevented, but only if countries acted swiftly together. ${ }^{3}$

I hope that the UK inquiry will recommend that, in future, scientific briefings will be separated from political briefings. Chris Whitty, England's chief medical officer, and Patrick Vallance, chief scientific adviser, and the various advisory committees they sit on, have for 18 months advocated a tougher, more precautionary approach to managing the pandemic than the government has seen fit to enact. However, the fact that they stand shoulder to shoulder with Boris Johnson at pandemic briefings gives the false impression that he is following their scientific advice, and that they are all in agreement.

A united front made sense at the outset, to announce the arrival of the pandemic, but thereafter there should have been separate and independent scientific briefings followed by the political briefing explaining the strategy that may, or may not, follow that science. The fact that so many experts have questioned the UK government's approach throughout this pandemic, and still are, with an urgent call for a global "vaccines-plus" action, shows how far scientists in and outside government are from agreeing what science we should be following. 4 Whether Hallett and her team will be able to draw firm conclusions on what we should have done at each stage of this pandemic remains to be seen. But until they have at least tried, in my view, it might be wise for those offered an honour to ask for it to be temporarily postponed. 


\section{OPINION}

Competing interests: $\mathrm{PH}$ is a recently retired NHS doctor, Private Eye's medical correspondent and author of the Sunday Times bestseller, Dr Hammond's Covid Casebook. He has never been offered an honour.

Provenance and peer review: commissioned, not peer reviewed

1 McKee M. Misconduct in public office?BMJ2021;375:n3015. doi: 10.1136/bmj.n3015. pmid: 34876464

2 Gurdasani D, McKee M. The parliamentary committee report on covid-19 response. BMJ 2021;375:n2530. doi: 10.1136/bmj.n2530. pmid: 34654707

3 Wenham C, Kavanagh M, Torres I, Yamey G. Preparing for the next pandemic. BMJ 2021;373:n1295. doi: 10.1136/bmj.n1295. pmid: 34020969

4 An open letter by a group of public health expertscliniciansscientists. Covid-19: An urgent call for global “vaccines-plus” action. BM/2022;376:01. doi: 10.1136/bmj.o1. pmid: 34980603 